\title{
AVALIAÇÃO DA QUALIDADE PAISAGÍSTICA PARA O USO TURİSTICO DO PARQUE DO INGÁ, MARINGÁ (PR)
}

\author{
EVALUATION OF THE LANDSCAPE QUALITY FOR TOURISTIC PURPOSE AT INGÁ \\ PARK, MARINGÁ, BRAZIL
}

\author{
Giuliano Torrieri Nigro¹, Bruno Luiz Domingos De Angelis²
}

\section{RESUMO}

Objetivando avaliar a qualidade visual da paisagem, para a melhora do gerenciamento do uso turístico no Parque do Ingá, localizado na região central da cidade de Maringá (PR), a presente pesquisa utilizou o método de análise da qualidade visual da paisagem, que foi dividido em duas etapas. A primeira consistiu na avaliação técnica da paisagem, por meio de fotografias, pelo método direto, por intermédio dos componentes de cada fotografia. A segunda etapa, pelas fotografias selecionadas na etapa anterior, consistiu na realização de entrevistas com os turistas que frequentam o Parque. As entrevistas permitiram determinar a preferência paisagística destes. Observou-se que as duas paisagens mais valoradas foram dois atrativos turísticos: o Jardim Japonês, como primeira colocada; e a Gruta Nossa Senhora da Glória, como segunda. Foi possível identificar a preferência por paisagens organizadas e com harmonia entre os elementos, e as que apresentaram poucos elementos e desarmonia foram avaliadas como menos qualitativa. Algumas fotografias apresentaram elementos depreciadores da qualidade visual do Parque. Também foi possível apontar o fator subjetivo, individual de cada pessoa, como determinante para a ordem de preferências. A presente metodologia permitiu conhecer os pontos de maior qualidade visual e os que depreciam a qualidade visual do Parque do Ingá.

Palavras-chave: Turismo; Paisagem; Áreas verdes; Parque urbano.

\section{ABSTRACT}

With the purpose of evaluating the landscape visual quality, to improve the management of touristic use at Ingá Park, located at the central region of Maringá city (PR), this research used the method of the landscape visual quality analysis, which was divided in two stages. The first one was the landscape technical evaluation through photographs, applying the direct method with the components of each photograph. The second step consisted in interviews with park tourists using the selected photographs in the previous step. The interview allowed this study to determine the tourists landscape preferences. It was observed that the two landscapes with more votes were two tourist attractions of the park: first, the Japanese Garden (Jardim Japonês), and, second, the Cave of Our Lady of Glory (Gruta Nossa Senhora da Glória). It was possible to identify the preference for organized landscapes with great harmony among the elements, instead of those with fewer elements presented with no harmony. Some photos showed elements responsible for reducing the visual quality of the park. It was also possible to identify a subjective factor, unique of each person, as decisive to choose the order of preferences. This methodology enabled knowing the points of highest and lowest visual quality of the Ingá Park.

Keywords: Tourism; Landscape; Green areas; Urban park.

Recebido em 01.06.2016 e aceito em 30.08.2016

1 Graduação em Turismo - Pontifícia Universidade Católica de São Paulo (PUC-SP) / Mestrado em Geografia - Universidade Estadual de Maringá -PR (UEM) / Doutorando em Geografia - UEM / Professor Colaborador - Universidade Estadual do Paraná FECILCAM - Campo Mourão, PR - gnigro2011@gmail.com

2 Professor do Departamento de Geografia, Universidade Estadual de Maringá (UEM), Maringá, PR - bucagen@uol.com.br Engenheiros 


\section{INTRODUÇÃO}

As últimas décadas foram marcadas por intenso processo de urbanização que levou ao aumento de problemas relacionados à saúde psicofísica das populações, nas grandes cidades. As áreas verdes urbanas, materializadas na forma de parques urbanos, ganharam destaque como alternativa ao modelo de vida nos grandes centros, marcando um período de procura por aumento da qualidade ambiental nas cidades. Representam o remanescente de algum contato que o cidadão urbano ainda tem com ambientes que possuem algumas características ou elementos naturais.

O espaço livre de construção é aquele destinado ao lazer público e à preservação ou implantação de vegetação. Nesse sentido, as áreas verdes são um tipo especial destes espaços livres de construção, no qual o elemento fundamental de composição é a vegetação (TOLEDO; SANTOS, 2008).

No geral, são áreas que englobam locais com predomínio de vegetação arbórea, praças, jardins e parques e que devem servir a toda população para os anseios de lazer (MORERO; SANTOS; FIDALGO, 2007). Estas áreas devem satisfazer três objetivos: ecológico-ambiental; estético; e lazer (BUCCHERI FILHO; NUCCI, 2006; GUZZO, 2006). Ecológico-ambiental em relação à manutenção do microclima local, abafamento de ruídos, controle de erosão (cobertura vegetal), melhoria da qualidade do ar e proteção de mananciais. Em relação aos efeitos estéticos, são visíveis na modificação do ambiente urbano, tornando-os mais agradáveis às vistas das pessoas.

$\mathrm{Na}$ questão do lazer, propicia espaços livres de construção para a prática de exercícios, socialização e contemplação. As áreas verdes não são necessariamente voltadas para a recreação e lazer, porém devem ser dotadas de equipamentos para oferecer esse tipo de opção (MAZZEI; COLSESANTI; SANTOS, 2007).

As áreas verdes urbanas agem simultaneamente sobre a dimensão física e mental do homem. Em relação ao lado físico: atenuando calor, absorvendo ruídos e filtrando partículas sólidas em suspensão no ar. No plano psicológico: atenua o sentimento de opressão do homem em relação às grandes edificações e contribui para a formação do senso estético (DE ANGELIS; LOBODA, 2005).

As áreas verdes urbanas que estão na pauta do turismo são, em sua maioria, os parques urbanos. Silva et al. (2012) os define como uma tipologia de áreas verdes que possui múltiplas funções e objetivos, entre eles: conservação da biodiversidade, realização de atividades de lazer, recreação e turismo.

Os parques urbanos, no contexto atual, não são apenas áreas de conservação e lazer para a população, mas também se configuram áreas de relevante interesse turístico pela sua 
paisagem e beleza cênica, mediante crescente demanda atual por um turismo alternativo, longe ainda de ser hegemônico, mas crescente, que visa romper com a clássica forma de turismo de massa, degradante, do ponto de vista socioambiental. Os parques, neste sentido, podem viabilizar e incentivar a atividade, pois dá certa identidade ao espaço urbano, constituindo-se uma "imagem" a ser exibida e consumida como mercadoria (SERPA, 2006). Também têm a característica de serem locais que propiciam beleza cênica, tanto para quem passa na região do entorno, quanto para quem o adentra.

Não há dúvida que o turismo é uma atividade que está intimamente ligada à paisagem, ela é um dos principais elementos que motivam a escolha dos locais a serem visitados pelo turista (PIRES, 2005). A dimensão visual da paisagem, aliada a outras formas de percepção, por parte do observador, constitui-se o principal apelo de atratividade para o turismo (PIRES, 1999). A paisagem deixa de ser considerada apenas como algo estético a ser observado e contemplado para se tornar importante recurso da atividade turística. Sua qualidade cênica é um dos principais motivos que levam pessoas a se deslocarem longas distâncias para alcançarem ambientes com características e elementos naturais.

A paisagem é um recurso do meio, que pode ser analisada e valorada. É uma realidade construída pelo indivíduo através da percepção de seu entorno. Enquanto ainda não percebida, não pode constituir-se como paisagem (CANTERAS, 1992).

A percepção visual da paisagem, sua interpretação e valoração podem auxiliar no planejamento e gestão de parques urbanos, sobretudo para o uso turístico. A valoração da paisagem serve como instrumento prático e objetivo para o gerenciamento de parques urbanos e a avaliação da qualidade visual desta tem se tornado importante ferramenta para agregar informações necessárias ao planejamento da paisagem (BULUT; YILMAZ, 2008)

Os parques urbanos possuem a característica de juntar os elementos naturais e urbanos, transformando-os em um produto turístico único e indissociável. A paisagem resultante é singular, e em função disso, transformada em importante recurso turístico (HENZ; OLIVEIRA, 2010).

A análise da paisagem para o turismo tem que levar em consideração a diferenciação de "visão da paisagem" que os turistas possuem em relação aos moradores locais. Em situações cotidianas, os moradores locais não observam a paisagem por considera-la comum, e, com isso, não reconhecem sua qualidade visual. O turista tem uma visão mais detalhada de determinada paisagem, que o morador não percebe em seu caminho para o trabalho ou para a escola (DIAS, 2010). Esse é o motivo da presente pesquisa: avaliar a preferência paisagística somente de turistas que frequentam a localidade em questão. 
Por entender que cada observador ou indivíduo capta um elemento da paisagem de forma diferenciada, Silva e Biondi (2013) apontam que estes elementos despertam interesse pelo local visitado e auxiliam possível estudo de valoração qualitativa da paisagem.

A presente pesquisa demonstra a necessidade de um estudo de valoração paisagística para o Parque do Ingá, na cidade de Maringá (PR), por entender a centralidade e a importância que este parque urbano, localizado na área central da cidade, possui para a dinâmica da cidade e sua população, mas também para a população flutuante, representada pelos turistas que o frequentam.

O estudo de valoração paisagística permitirá identificar os pontos de maior atratividade, revelando os locais de melhor qualidade visual, assim como os locais de pior qualidade. Os pontos destacados como de melhor qualidade podem ser sugeridos como atrativos turísticos e os de pior qualidade deverão receber, por parte dos administradores, maiores cuidados e melhorias na qualidade visual.

Portanto, o presente trabalho objetiva avaliar a qualidade visual da paisagem do Parque, a fim de conhecer os principais elementos que valorizam e os que depreciam a qualidade visual do mesmo, podendo auxiliar no planejamento e gestão para a prática turística.

\section{MATERIAL E MÉTODOS}

\section{Caracterização da área de estudo}

O Parque do Ingá localiza-se na região central do perímetro urbano de Maringá (PR), entre as Avenidas São Paulo, Anchieta, Neo Alves Martins, Laguna e Jucelino Kubitschek. Situa-se a uma altitude de 557 metros e compreende uma área de $474.300 \mathrm{~m}^{2}$ (Figura 1).

É banhado pelo Córrego Moscados, pertencente à bacia hidrográfica do rio Ivaí. Apresentava diversas nascentes, porém, no ano de 1970, o córrego foi represado, estabelecendo-se, a partir de então, um grande lago na região central do Parque.

O Parque do Ingá foi criado com o intuito de preservar a história cultural e natural da cidade, enquadrando-se como área verde urbana, por ser um remanescente de vegetação nativa na região central de Maringá, e no ano de 1990 foi transformado em Área de Preservação Permanente (BOVO, 2011).

Caracterizado como área verde urbana e por se encontrar em zona central, os gestores do Parque têm o desafio de conciliar conservação ambiental com espaços amplos de lazer para a população, gerando conflitos de interesses por parte da administração pública. 
Parque tem a função de ser local destinado à conservação natural e, ao mesmo tempo, área de lazer e recreação para os cidadãos.

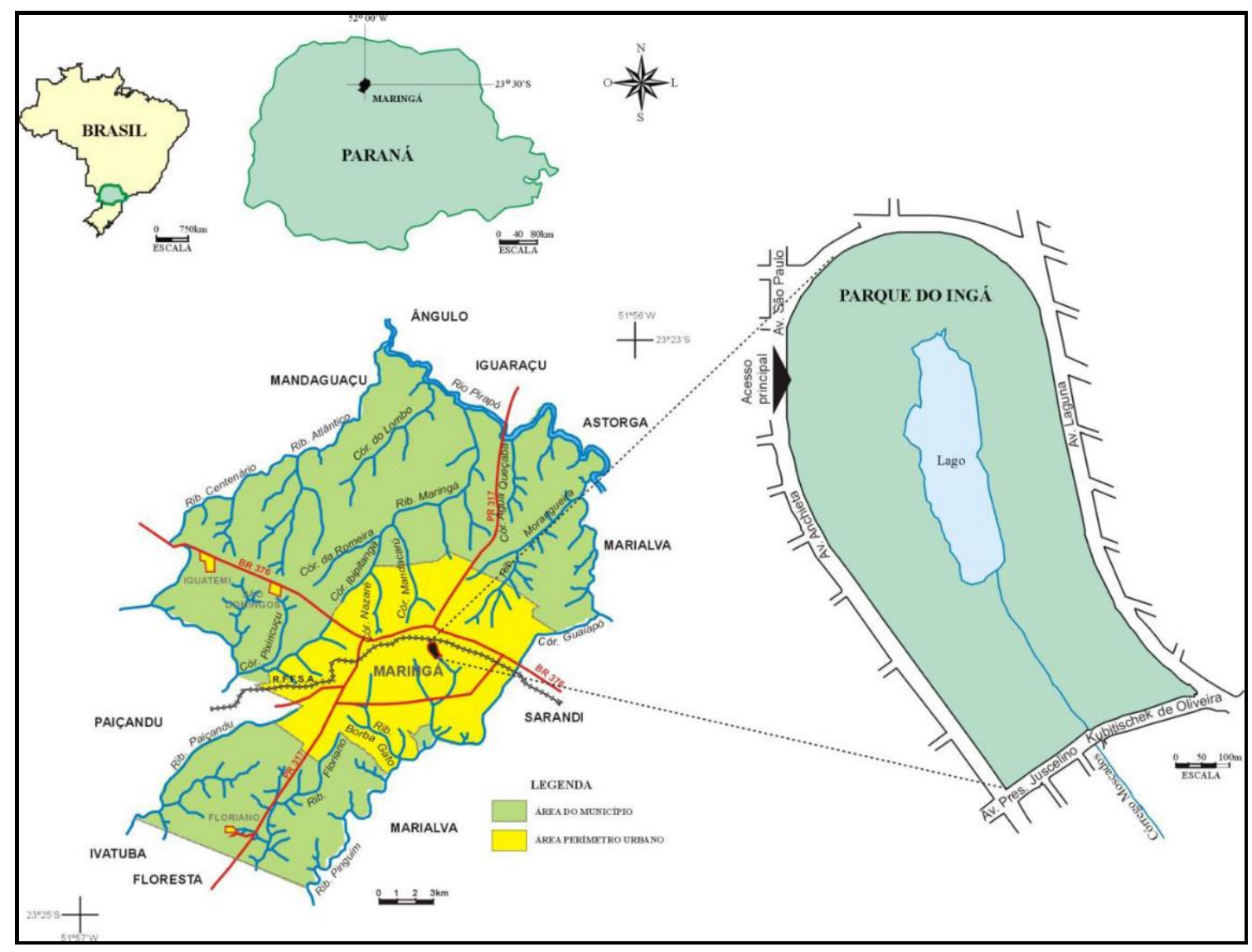

Figura 1. Localização Geográfica da Área de Estudo

Fonte: Mansano, Sarrão e Sarrão (2011)

Figure 1. Geographic location of the Study Area

Seu interior é formado por trilhas e caminhos ecológicos, no qual o turista pode contemplar, observando a fauna e flora do local. Possui diversos atrativos turísticos voltados à contemplação da paisagem e lazer, em ambientes naturais.

Próximos à entrada do parque localizam-se a estátua do fundador do Parque do Ingá, o ex-prefeito Adriano Valente, e o abrigo da locomotiva. Na parte oeste do lago localizam-se o Jardim Japonês e a Gruta Nossa Senhora da Glória.

$\mathrm{Na}$ área central encontra-se o lago, com $55.000 \mathrm{~m}^{2}$. Ao redor do lago há uma pista de corrida e caminhada que o contorna, e a área onde estão o ancoradouro e o restaurante.

\section{Procedimentos Metodológicos}

A análise da qualidade visual do Parque do Ingá foi realizada por meio do método direto utilizando fotografias e entrevistas com os turistas. No método direto, insere-se a análise 
da qualidade visual da paisagem, tomando-se por base a totalidade dela pela visualização local ou por substitutos (fotos e gravuras), com valoração efetuada pelo público (PIRES, 1993).

A metodologia dividiu-se em duas etapas: a primeira realizou avaliação técnica da paisagem, por meio da valoração de seus componentes, visando à análise da qualidade visual para o turismo (objetiva); a segunda possibilitou avaliação subjetiva, por meio de entrevistas estruturadas, indicando a preferência paisagística dos turistas que frequentam o Parque do Ingá (subjetiva).

No tocante à primeira etapa, utilizou-se o método direto de análise da paisagem, por meio de substitutos (fotografias), para facilitar sua aplicação. Essa etapa consistiu na avaliação técnica de 30 fotografias selecionadas, de forma aleatória, com a função de qualificar seus componentes, de acordo com os pesos estabelecidos, previamente, para a valoração da qualidade visual de cada uma. De acordo com os valores estabelecidos, em função deste critério, as fotografias foram separadas em três níveis: Classe alta $(A)$, baixa $(B)$ e média $(M)$. Selecionaram-se duas fotografias de cada classe, representando o limite extremo de cada uma (a melhor e a pior colocada), totalizando seis fotos que foram utilizadas para a etapa seguinte.

A segunda etapa permitiu a avaliação subjetiva das seis fotografias selecionadas, indicando a preferência paisagística por parte do turista, realizada por meio de entrevistas, objetivando traçar um perfil dos turistas durante o período de aplicação, assim como determinou a preferência paisagística destes, uma vez que os mesmos colocaram em ordem de preferência da melhor para a pior as fotografias selecionadas, de acordo com sua opinião. Justificou-se o porquê da escolha da melhor e da pior fotografia, sendo possível, assim, estabelecer a fotografia que representa a melhor qualidade visual da paisagem e a que mais a deprecia.

\section{Análise da Qualidade Visual da Paisagem para o Turismo}

Foi escolhido o método direto por permitir avaliar todos os componentes da paisagem, de forma direta, objetiva, atribuindo valores a cada um deles. O presente método procura diminuir a subjetividade nas escolhas das fotografias de modo a analisá-las de forma objetiva.

Baseado no método de Bobrowski, Biondi e Vashchenko (2010), foram tiradas fotografias nos locais de maior acessibilidade do parque, tais como mirantes, trilhas, bosques, lagos e outros. Do total de fotografias obtidas, sorteou-se aleatoriamente 30 fotografias (Figura 2) para representar a paisagem observada no Parque. Escolheu-se essa quantidade para que não represente um número grande que atrapalhe a efetivação da metodologia, e nem que seja um número que não dê, minimamente, representatividade ao local. Os substitutos da paisagem 
foram avaliados de acordo com os valores estabelecidos, em função da presença dos componentes naturais e antrópicos em cada paisagem.
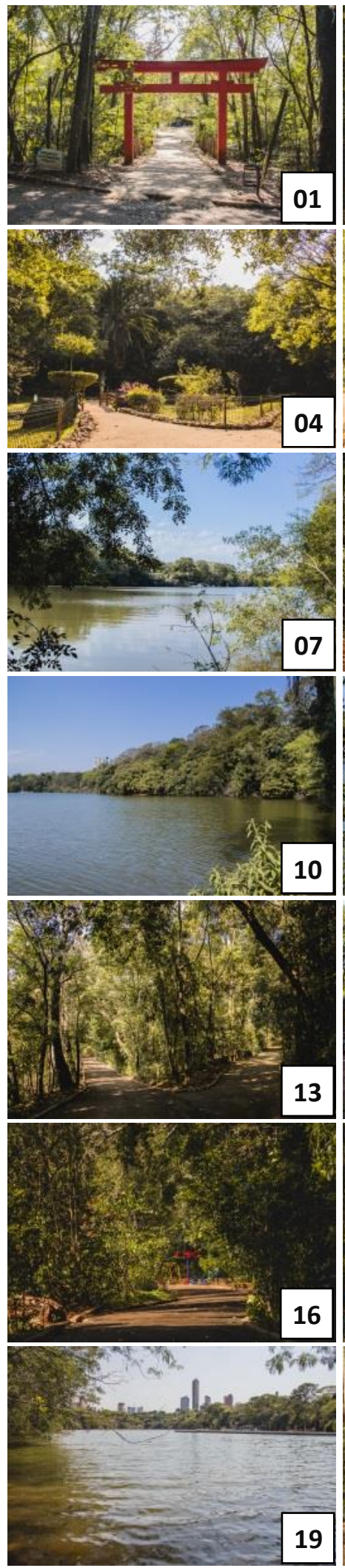
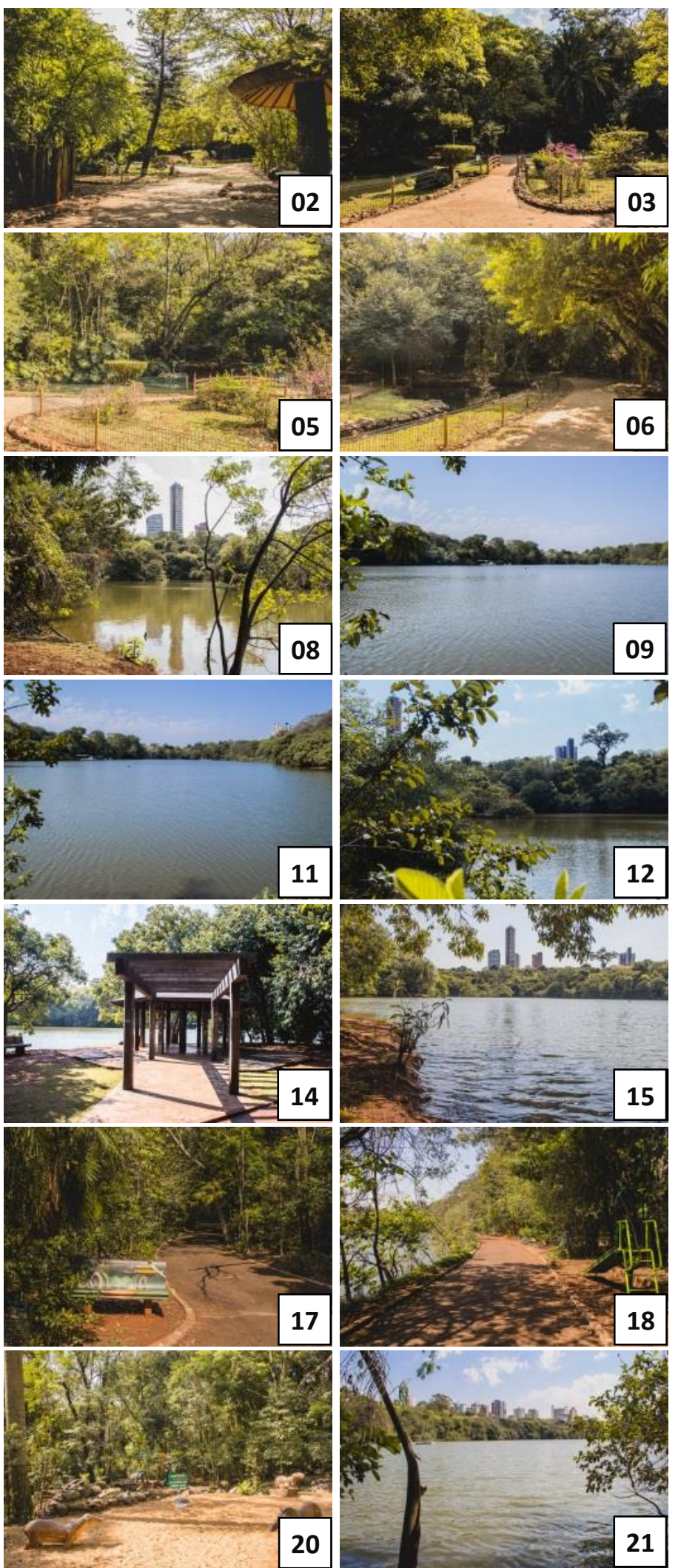

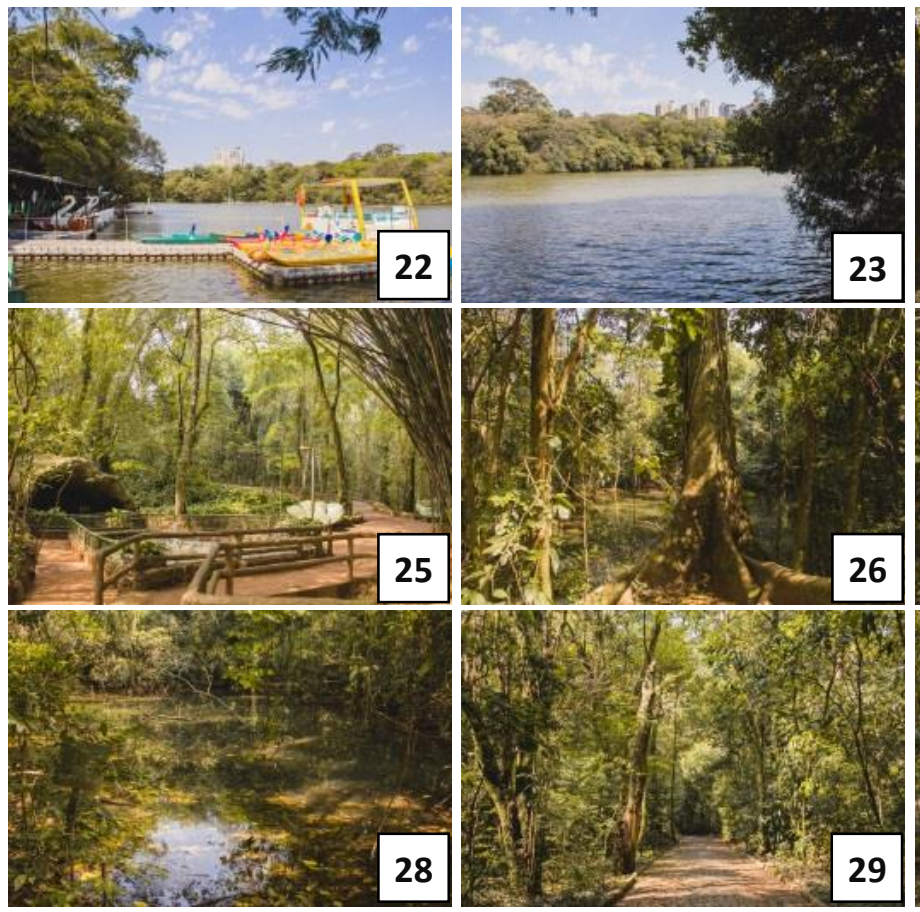

29

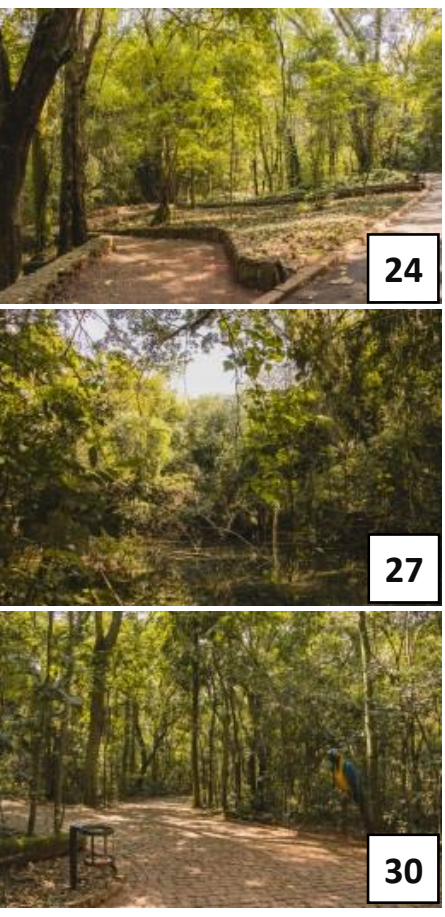

Fonte: Fotos do autor (2015).

Figura 2. Fotografias do Parque do Ingá Selecionadas para Avaliação Técnica

Figure 2. Photos of Ingá Park Selected for Technical Evaluation

Os pesos estabelecidos de cada componente foram adaptados da metodologia Bobrowski, Biondi e Vashchenko (2010). (Tabela 1).

Tabela 1. Valoração dos Componentes da Paisagem do Parque Table 1. Valuation of the Park Landscape Components

\begin{tabular}{|c|c|c|c|}
\hline Componente Natural & Peso & Componente Antrópico & Peso \\
\hline Céu & 1,0 & Urbanização & $-3,0$ \\
\hline $\begin{array}{l}\text { Vegetação: } \\
\text { a) Herbácea } \\
\text { b) Arbórea }\end{array}$ & $\begin{array}{l}3,1 \\
3,2\end{array}$ & $\begin{array}{l}\text { Arquitetônico: } \\
\text { a) Portal } \\
\text { b) Acessos } \\
\text { c) Grutas } \\
\text { d) Pontes } \\
\text { e) Grades e cercas } \\
\text { f) Obras de arte } \\
\text { g) Elementos } \\
\text { arquitetônicos } \\
\text { h) Equipamentos }\end{array}$ & $\begin{array}{l}3,05 \\
3,05 \\
3,2 \\
3,1 \\
-2,0 \\
3,2 \\
3,05 \\
3,0\end{array}$ \\
\hline $\begin{aligned} & \text { Água: } \\
& \text { a) Córrego } \\
& \text { b) Lago }\end{aligned}$ & $\begin{array}{l}3,1 \\
3,2\end{array}$ & & \\
\hline
\end{tabular}

Fonte: Bobrowski, Biondi e Vashchenko (2010), adaptação do autor. 
De acordo com a metodologia, foram considerados os seguintes componentes naturais da paisagem: vegetação, céu, água; componentes antrópicos: elementos que representam presença de urbanização e elementos arquitetônicos do parque. Cada componente recebeu uma valoração, no caso dos elementos naturais recebeu-se valoração positiva, representando melhor qualidade visual, assim como alguns representantes arquitetônicos. No entanto, a presença de urbanização dentro e no entorno do Parque diminui os componentes naturais da paisagem, recebendo, assim, valoração negativa.

Em relação aos componentes naturais considerou-se que o elemento céu teria menor peso $(1,0)$, de forma a não afetar significativamente a valoração e não alterar os valores dos componentes terrestres. Os elementos água e vegetação foram subdivididos, recebendo peso alto. A vegetação dividiu-se em herbácea $(3,1)$ e arbórea $(3,2)$, sendo a segunda mais atrativa por representar um ambiente com menor frequência de intervenções antrópicas, porém a diferença entre as duas é mínima, com o intuito somente de diferenciá-las e evitar que uma se sobressaia de maneira exagerada sobre a outra. A água subdividiu-se em córrego $(3,1)$ e lago $(3,2)$, sendo o lago mais atrativo, possuindo um peso maior por ser mais importante na qualidade visual. Os elementos arquitetônicos observados foram: portal, acessos, grutas, pontes, grades e cercas, obras de arte, elementos arquitetônicos e equipamentos. Todos receberam pesos diferenciados em relação à sua importância arquitetônica e turística. Merecem destaque as grades e cercas, que receberam valoração negativa $(-2,0)$, em função da depreciação que causam na qualidade visual.

A quantificação dos componentes e elementos da paisagem nas fotografias foi efetuada a partir de impressões de quatro fotografias $(9 \times 13 \mathrm{~cm}$ cada) em uma folha de papel A4, e sobre essa foi colocado um papel transparência reticulado, totalizando 117 quadrículas por fotografia. De acordo com a disposição das fotografias no papel, contou-se o número de quadrículas existentes de um determinado componente da paisagem. No caso de em uma quadrícula ocorrer a presença de mais de um componente, considerou-se o elemento mais frequente nela.

Assim, a qualidade visual da paisagem de cada uma das 30 fotografias foi obtida através da somatória dos valores adquiridos na multiplicação da quantidade dos elementos presentes, pelo peso de cada elemento.

\section{Análise da Preferência dos Visitantes}

Realizou-se entrevista abrangendo dados como gênero, faixa etária e grau de instrução, a fim de analisar se há relação do perfil dos turistas com as preferências paisagísticas. Se o visitante declara ser turista, devem-se coletar os demais dados da pesquisa 
e pedir para que coloque em ordem de preferência as seis fotografias selecionadas pelo método direto de análise da paisagem. O entrevistado deve colocar as fotografias em ordem de acordo com a sua preferência, justificando a escolha da primeira e última colocada.

A pesquisa foi efetuada somente com pessoas que se declararam turistas, haja vista que o intuito é verificar se a referida opinião está de acordo com os critérios de avaliação técnica da qualidade visual da paisagem para o turismo.

O turista e o autóctone possuem visões diferentes a respeito do meio ambiente. A cultura influencia no condicionamento da percepção e dos valores ambientais das pessoas. Por isso, no presente estudo, considerou-se apenas a visão do turista do Parque do Ingá.

A metodologia utilizada para o cálculo da amostra para a aplicação dos questionários baseia-se na pesquisa quantitativa, probabilística, por amostragem representativa dos visitantes do Parque do Ingá, realizada no período de 23 de janeiro a 09 de fevereiro de 2016, de terça a domingo (entre as 08 e 17h), com entrevistas pessoais por meio de questionário padronizado e estruturado para a coleta. A amostra foi projetada com base no número médio de visitantes do Parque (7.000 adultos e 700 crianças - dados fornecidos pelo Parque do Ingá em levantamento realizado em 2014, por contador manual, no período das 8 as 16hrs de terça a domingo). Considerando erro amostral de 10\%, com nível de confiança de 99\%, foi necessária amostra de 163 indivíduos.

\section{RESULTADOS E DISCUSSÃO}

\section{Resultado da Análise Técnica das Fotografias}

No geral, as paisagens de classe alta (A) apresentaram alta quantidade de elementos de vegetação, pouco elemento céu e pouca urbanização, em relação às demais classes. São fotografias tiradas no interior do parque, as quais mostram ambientes internos e da parte do lago, algumas contando também com obras de arte e componentes arquitetônicos. As paisagens de classe baixa (B) apresentaram, no geral, grande quantidade de elementos de urbanização, em relação às demais classes. Apresentaram, também, considerável quantidade de elemento céu e poucos elementos de vegetação ou lago. As de classe média (M) apresentaram elementos equilibrados de vegetação ou lago, mas possuem um número maior de elemento céu, em relação à classe alta.

Observou-se que entre os elementos naturais, quanto maior a presença de céu menor a presença de vegetação arbórea e lago, afetando negativamente a valoração das paisagens, uma vez que a maior presença deste componente causa, consequentemente, a menor presença de componentes que possuem maior valoração. 
Devido ao sistema de valoração adotado, a predominância da melhor qualidade visual para paisagens ocorreu onde havia maior proporção de vegetação arbórea ou lago, conforme valor obtido pela análise da paisagem da fotografia 16, por exemplo. Também se observou a obtenção de valores menores para paisagens que apresentaram maior proporção dos componentes: urbanização, grades e cercas, representando paisagens com mais alto grau de depreciação visual da paisagem natural.

As paisagens das fotografias 16 e 25 foram classificadas como qualidade visual alta na análise técnica, representando, respectivamente, a melhor e a pior colocada nos limites da classe (A). As duas têm a característica de serem fotografias com grande proporção de componentes vegetais e sem nenhum componente que causa depreciação da qualidade visual, como é o caso da urbanização, por exemplo. A figura 16 possui a maior proporção de vegetação, seguida dos componentes caminhos e equipamentos. A figura 25 possui uma proporção menor de componentes de vegetação, mas conta também com a presença da gruta, que recebeu valoração alta.

As fotografias 27 e 3 foram classificadas como qualidade visual média, representando, respectivamente, a melhor e pior colocada nos limites da classe (M). A paisagem que representa a fotografia 3 possui certo equilíbrio dos elementos que a compõe, com grande proporção de componente vegetal, mas com a presença de componente céu. Porém, o que marcou maior depreciação visual nesta paisagem foi a presença de grades, fazendo com que esta se desvalorizasse, não recebendo avaliação alta. Já a paisagem da fotografia 27 apresentou grande quantidade de componentes de vegetação, mas também conta com a presença do componente céu e córrego, deixando de pontuar de maneira mais efetiva na análise valorativa.

Com relação às paisagens das fotografias 19 e 22, foram classificadas como qualidade visual baixa, representando, respectivamente, a melhor e a pior colocada nos limites da classe (B). A foto 19, apesar de apresentar significativa proporção de elementos de alta valoração, como é o caso do lago, apresenta alta proporção do componente céu e uma grande proporção do componente urbanização, o que depreciou demasiadamente a qualidade visual desta. A paisagem de número 22 foi a pior avaliada pela presente metodologia, pois apresenta pouca ocorrência de componentes de vegetação e lago, mas grande ocorrência de componente céu, equipamentos e urbanização. 


\section{Fotografias selecionadas}

As seis fotografias utilizadas para a avaliação nas entrevistas foram as de número 03, 16, 19, 22, 25 e 27. Porém, para facilitar a aplicação da metodologia e da análise dos dados, foram adotadas as letras $A, B, C, D, E, F$, respectivamente, das fotografias selecionadas (Figura 3).
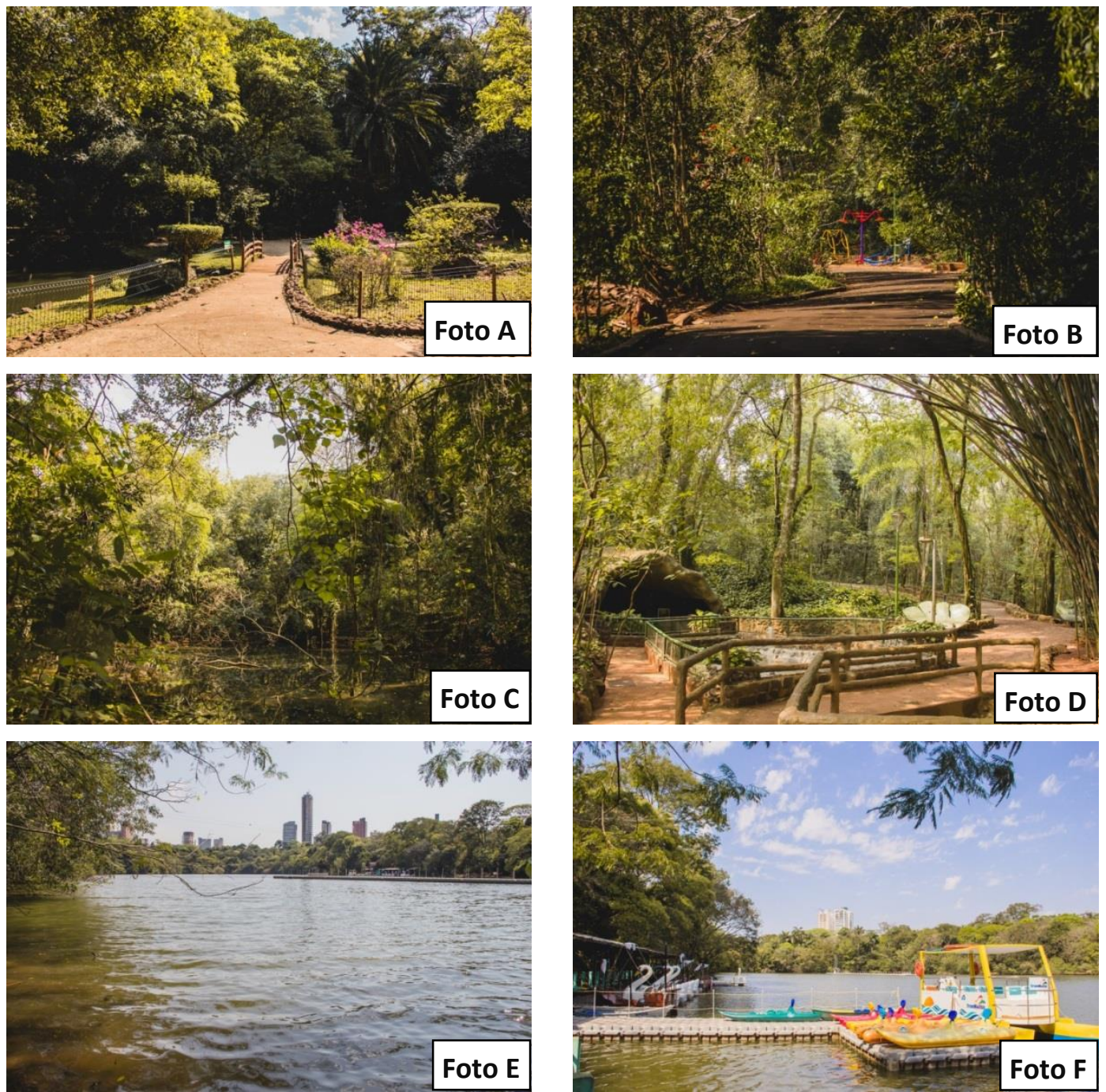

Fonte: Fotos do autor (2015)

Figura 3. Ordem das fotos selecionadas para pesquisa com turistas

Figure 3. Order of the photos for the research with tourists

Foi realizado levantamento, por meio dos questionários, da ordem de preferência das fotografias, em todas as colocações. A Fotografia A foi escolhida pela maioria dos entrevistados como a que representa melhor qualidade visual da paisagem para o Parque do Ingá. A Fotografia $C$ foi a última na preferência da maioria, sendo eleita a que mais deprecia a qualidade visual. 
A correlação das variáveis e análises cruzadas foi efetuada apenas para a primeira e última colocada, devido o enfoque do presente trabalho em eleger a paisagem mais valorada $\mathrm{e}$ a menos valorada para o turismo. Foram, ainda, analisadas as demais fotografias quanto à motivação da escolha de cada uma delas como primeira e última colocada.

Pretendeu-se, com as análises em questão, verificar se há relação entre as variáveis da pesquisa e as preferências paisagísticas, e verificar quais fotografias representam a melhor qualidade visual do parque e a que mais deprecia.

\section{a) Fotografia $\mathbf{A}$ - primeira colocada}

Dos 163 entrevistados, registrou-se a fotografia A como a de melhor qualidade visual, escolhida por 38,04\% dos entrevistados que frequentaram o Parque do Ingá, no período de realização da pesquisa.

Trata-se de uma fotografia da parte frontal do Jardim Japonês, importante atrativo turístico do Parque do Ingá. Apresenta ornamentos como pontes e bonsais. Possui grande número de componente de vegetação arbórea, o que valoriza a paisagem. Mas, apesar da predominância do verde, o que mais chamou a atenção dos turistas foi a harmonia e organização dos elementos na paisagem. A fotografia representa essa organização, dando aspecto de ambiente limpo e contemplativo. Também apresenta elementos coloridos em harmonia com o restante do local.

A maioria dos entrevistados que escolheram a fotografia $A$ como preferida tiveram como motivo hegemônico: harmonia/ organização dos elementos $23,31 \%$; seguido de beleza natural (vegetação) 7,36\%; colorido da paisagem 2,45\%; assim como, sensação de paz, calma e tranquilidade, que também ficou com 2,45\%; Fácil acesso/ entrada 1,23\%; organização do local / limpeza e lugar aberto e iluminado com 0,6\% cada (Figura 4).

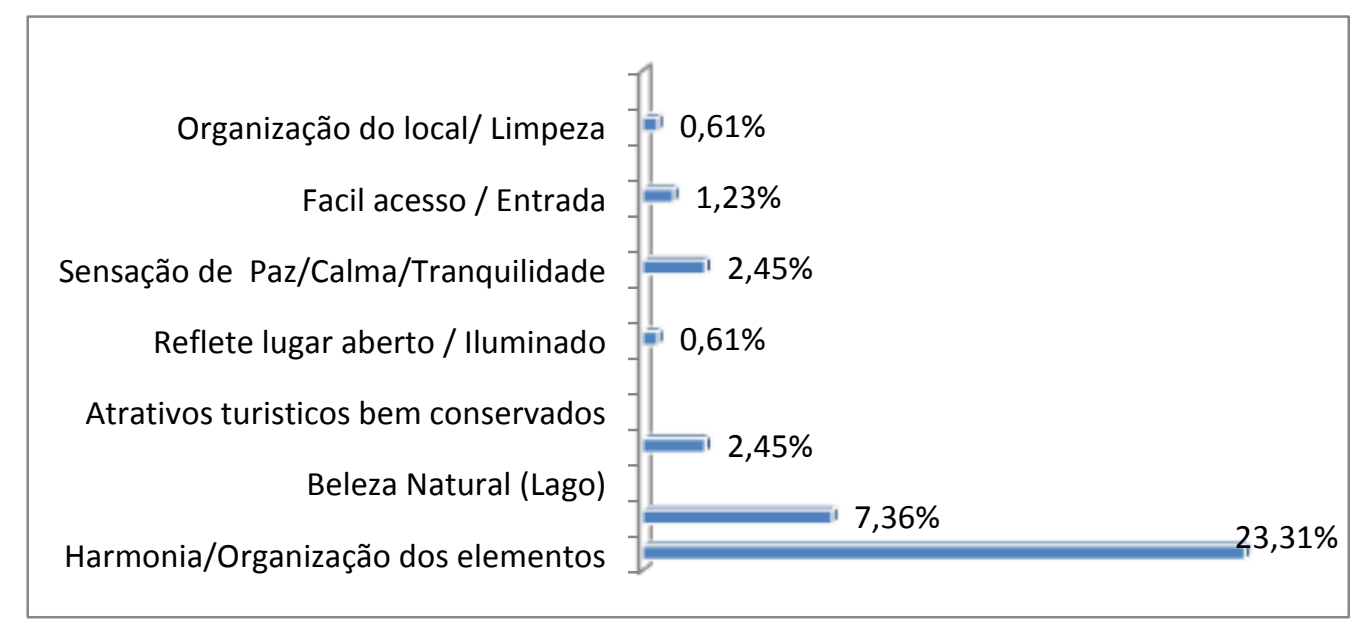

Fonte: elaborado pelo autor (2016).

Figura 4. Motivos da escolha da Foto A como $1^{\text {a }}$ colocada

Figure 4. Reasons for the choice of Photo $A$ as $1^{\text {st }}$ place 


\section{b) Fotografia C - última colocada}

A fotografia $\mathrm{C}$ foi registrada com a pior qualidade visual das seis fotografias analisadas na presente pesquisa, por $39,88 \%$ dos entrevistados.

Trata-se de uma fotografia tirada da área de trás de onde se localiza a Gruta Nossa Senhora da Glória. Caracteriza-se por ser um local com aspecto de abandono e presença de material orgânico no córrego represado.

A foto possui número expressivo de componentes de vegetação e água, mas não há organização e harmonia de seus componentes. Outro aspecto a ser observado é a pouca variedade de elementos expressos na fotografia.

Também foi efetuada análise dos principais motivos que levaram os entrevistados a escolherem a fotografia $\mathrm{C}$ como a de pior qualidade visual, em relação às demais fotografias analisadas (Figura 5). Em sua maioria, os entrevistados alegaram se tratar de paisagem com aspecto de abandono, representando $14,11 \%$ do geral das entrevistas. O motivo poucos elementos indicou $11,66 \%$, e ambiente fechado indicou $11,04 \%$.

Nota-se, em uma primeira análise, que o mesmo critério de escolha dos entrevistados foi adotado nas duas fotografias que representam os dois extremos. Neste caso, a falta de elementos ou presença de um único elemento foi determinante para a escolha dessa fotografia como última colocada. $\mathrm{O}$ aspecto de abandono remete exatamente à falta de harmonia presente na fotografia $F$. No que se refere ao ambiente fechado, este remete à falta de variedade de elementos e certo abandono.

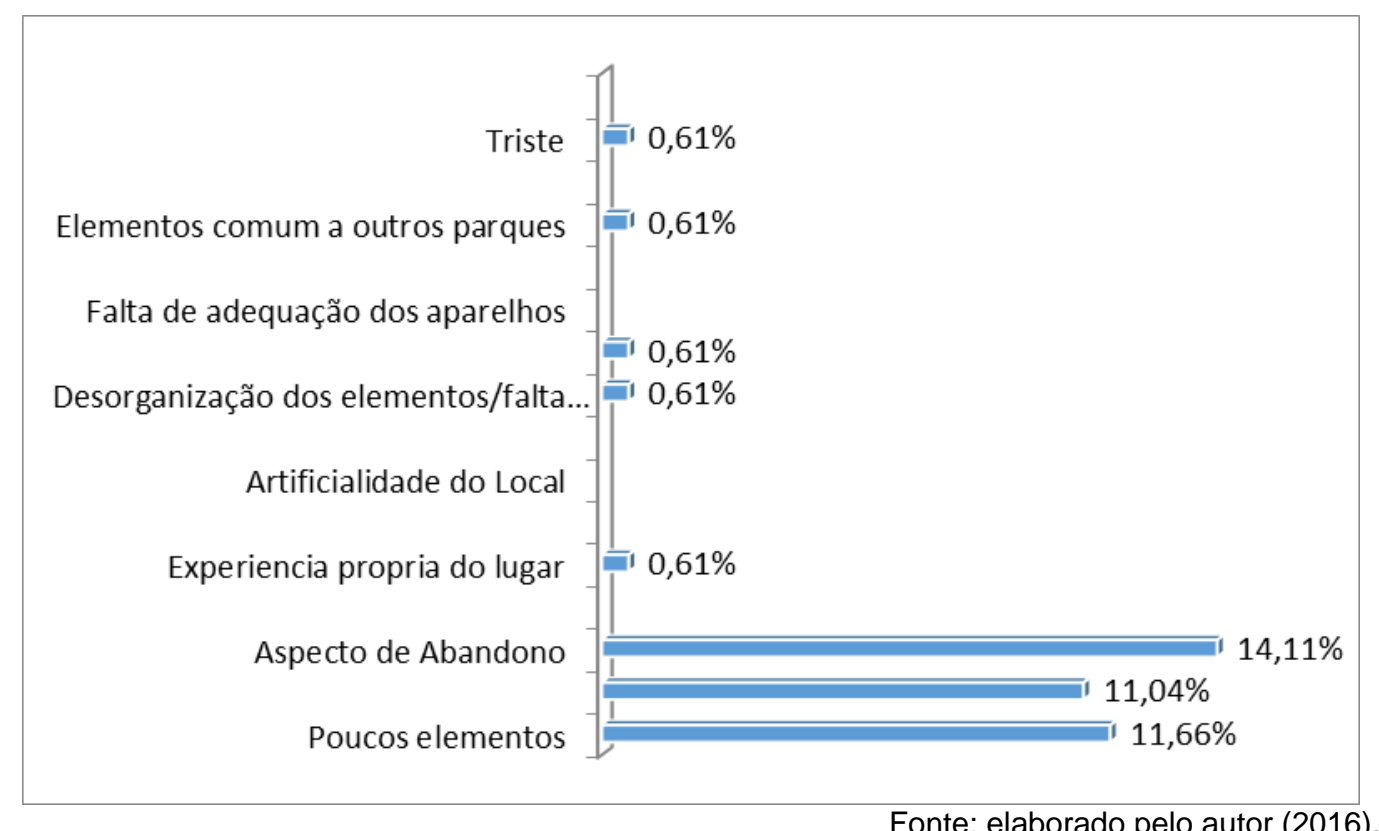

Figura 5. Motivos da escolha da foto $\mathrm{C}$ como $6^{\mathrm{a}}$ colocada

Fonte: elaborado pelo autor (2016).

Figure 5. Reasons for the choice of Photo $C$ as $6^{\text {th }}$ place 


\section{c) As demais fotografias}

As demais fotografias (D, F, E e B) não foram classificadas como primeira ou última colocada. Porém, cabe uma breve análise destas em relação às preferências dos entrevistados.

A fotografia $D$ foi a preferida pelos entrevistados na segunda $(26,09 \%)$ e terceira $(26,88 \%)$ colocação na ordem de preferências paisagísticas. Trata-se de uma fotografia tirada na área da Gruta Nossa Senhora da Glória. Foi indicada como paisagem com equilíbrio de elementos naturais e antrópicos, limpa, organizada, apresentando equilíbrio harmônico de todos os elementos, mas que prevalece o verde da vegetação.

A fotografia $E$ foi a mais votada na posição quarta colocada $(25,47 \%)$, indicando visão de depreciação da qualidade visual por uma parte dos entrevistados. Trata-se de uma fotografia do lago e em segundo plano apresenta presença de prédios, indicando elementos de urbanização. Possui componente vegetação e a predominância de componentes lago e céu. Foi indicada como fotografia que possui poucos elementos e se caracteriza pelo aspecto de abandono. A mistura do urbano com o natural, nesse sentido, também foi indicado como um dos principais fatores depreciativos desta paisagem.

A fotografia B foi a mais votada como quinta colocada $(34,16 \%)$, apresentando, então, forte teor depreciativo, em relação às outras selecionadas. Trata-se de uma fotografia de um caminho que leva à Academia da Primeira Idade (API), no interior do parque. Apesar da predominância de componentes vegetais, a fotografia foi indicada como quinta colocada por remeter a um ambiente fechado e por conter poucos elementos. Porém, a experiência do lugar contou de forma negativa, pois em alguns dias das entrevistas, em função das fortes chuvas, o local estava repleto de lama. Isso pode ter alterado, de forma significativa, o resultado da pesquisa, contrariando a análise objetiva que caracterizou a paisagem de forma positiva.

\section{Resultados da Preferência Paisagística do Turista}

A pesquisa foi realizada com 163 indivíduos que se declararam turistas e visitavam o Parque do Ingá no momento de suas entrevistas. O perfil traçado aqui representa o de uma demanda específica de turistas que se deslocam a Maringá em períodos de verão, férias escolares e trabalhistas. Com isso, o presente trabalho não pretende traçar um perfil geral dos turistas do Parque, visto que demandaria mais tempo e maior número de amostras para a efetivação da pesquisa com esse intuito.

São muitos os fatores que determinam as características de uma demanda turística. Esta pode sofrer mudanças significativas em relação ao período em que a pesquisa é efetuada, 
havendo impossibilidade de definir com precisão as características reais desse tipo de demanda, pois esta é composta de indivíduos e grupos heterogêneos. Além disso, é possível que se altere significativamente o perfil dos turistas em relação ao período do ano em que as pesquisas são realizadas (ANDRADE, 2006).

A grande maioria dos entrevistados é composta por brasileiros, e somente 3,07\% dos turistas são oriundos de outros países (Argentina 1,23\%, Italia1,23\%, Espanha 0,61\%). Apesar do número de turistas estrangeiros ser pequeno e influenciar pouco na pesquisa, este dado serve para indicar a presença deste tipo de turista na região.

A pesquisa mostrou que $58,23 \%$ dos visitantes são do estado do Paraná, seguido por $29,11 \%$ de São Paulo. O estado de Santa Catarina vem em seguida com 3,16\%. Os estados de Minas Gerais, Mato Grosso do Sul e Mato Grosso apresentaram cada um 1,90\% dos entrevistados. Do Pará 1,27\%, e os Estados: Rio Grande do Sul, Espírito Santo, Distrito Federal e Bahia apresentaram cada um 0,6\%.

Do total dos entrevistados, $53 \%$ são do sexo feminino e $47 \%$ do masculino. Da amostra de entrevistados em outros estados, observa-se $51,23 \%$ feminino e $45,68 \%$ masculino. No Paraná a proporção é de 33,76\% mulheres para $24,20 \%$ de homens, já no estado de SP é de $11,46 \%$ feminino e $17,83 \%$ masculino.

A faixa etária predominante dos entrevistados foi a de 19 a 28 anos, com 29,01\%. Dos 28 aos 37 anos de $25,93 \%$, e de 37 a 46 anos de $20,37 \%$.

Com relação ao grau de instrução, $41,72 \%$ tem curso superior, $39,26 \%$ o ensino médio, e 15,34\% possuem pós - graduação.

Pode-se afirmar que não houve qualquer correlação das variáveis: gênero, idade e escolaridade com as escolhas e preferências paisagísticas por parte dos entrevistados.

A presente pesquisa mostrou-se satisfatória em relação às escolhas paisagísticas e as motivações subjetivas de cada indivíduo. Foi possível, dentro do universo amostral, estabelecer relações de preferências a determinados tipos de paisagem, mostrando os principais elementos que valorizam ou depreciam a qualidade visual destas, permitindo propor melhor gerenciamento do uso turístico ao Parque do Ingá, por parte de sua administração.

No que se refere à fotografia $A$, a pesquisa demonstrou que o elemento vegetação é importante, mas não o principal, apontando para uma preferência mais pautada na harmonia dos elementos e na organização destes, mostrando que um só componente, muitas vezes, acaba por depreciar a qualidade paisagística da fotografia.

$\mathrm{Na}$ análise técnica da paisagem foi dada elevada ênfase às grades que cercam o jardim como depreciadoras de sua qualidade visual. No entanto, as pesquisas demostraram o contrário, que a organização do conjunto dos elementos e harmonia, em uma paisagem organizada e limpa, se sobressaem a esse fator de depreciação. Observa-se, ainda, que as 
grades possuem coloração verde, são baixas e finas, muitas vezes passando despercebidas pelos visitantes. De fato, contrariando a análise objetiva da paisagem, essa fotografia exemplifica e demonstra o interesse da maior parte dos usuários por paisagens organizadas e harmônicas e os fatores de qualidade visual são significativamente maiores que os depreciadores.

O mesmo se repete na fotografia $D$, apontando a preferência dos turistas por ambientes organizados e harmônicos, com presença de vegetação e componentes arquitetônicos ou antrópicos que interajam com o ambiente, sem sobrepô-lo.

A presente pesquisa corrobora com a visão de Lemes e Neves (2007), no qual afirmam que a presença de elementos naturais é um fator de valoração positiva na paisagem destinada ao uso turístico. Está de acordo também com a visão de Vieira, Kozera e Biondi (2007), que afirmam que a preferência paisagística dos entrevistados está associada a naturalidade da paisagem, com o equilíbrio e harmonia entre os elementos, pois sua apreciação se deve a um conjunto de fatores relacionados com a condição em que se apresentam e sua inserção no ambiente.

Também vai de encontro ao que afirma Canteras (1992), que a diversidade de elementos expressa uma variedade paisagística que possui mais valor do que uma paisagem homogênea, devido à ausência de monotonia nas fotografias. Isso explica a escolha das fotografias A e D como as preferidas dos entrevistados, assim como o motivo de sua escolha, corroborando com a visão de Bobrowski, Biondi e Vashchenko (2010), para os quais a vegetação não é fator determinante e elemento de maior peso para a atribuição de beleza às paisagens abordadas, muito embora seja elemento importante na valoração da paisagem, 0 que explica a escolha da fotografia $C$ como a última colocada, pois é demasiadamente composta por um único componente, o vegetal. Além de possuir basicamente um único elemento, o apresenta de forma desorganizada, além de representar uma paisagem fechada.

A questão da mistura do urbano com o natural foi elemento mais depreciativo, no conjunto das paisagens, do que valorativo, contrariando o que se discutiu na parte teórica, onde se afirmou que a paisagem composta por elementos naturais, dentro do espaço urbano, pode ser altamente valorativa em função da mistura dos elementos urbanos e natural.

Com relação a alguns resultados, o método de análise objetiva da paisagem, por meio de valoração dos componentes paisagísticos não correlacionou com a pesquisa subjetiva. É o caso da fotografia $B$ que foi classificada como nível $(A)$ na análise objetiva, imaginando-se que seria uma das preferidas dos turistas, mas se mostrou o contrário, sendo relacionada como a segunda pior em termos de qualidade visual. Nesse caso, a experiência pessoal dos entrevistados contou negativamente, provando que a fotografia não substitui o lugar, e a 
análise de entrevista é completamente subjetiva, podendo ser alterada de acordo com as convicções de cada indivíduo.

Também, esperava-se que a fotografia $C$ estaria entre as preferidas dos turistas, pois representaria o "verde" do Parque. Mas, provou-se que os entrevistados preferem paisagens mais harmônicas e organizadas, tendo elementos naturais e antrópicos que se relacionam positivamente.

Por fim, é importante observar que as duas primeiras fotografias mais bem valoradas como preferência dos entrevistados são dois dos principais atrativos do Parque do Ingá, mostrando o cuidado deste com o aspecto visual destas localidades. Um ponto importante dessa pesquisa é indicar que esses locais devem permanecer conservados e equipados para atender a sua demanda turística.

\section{CONCLUSÃO}

Por meio do presente trabalho, procurou-se demonstrar a importância da avaliação da qualidade visual da paisagem para o uso turístico em um parque urbano com as características e centralidade que é inerente ao Parque do Ingá, uma das mais importantes áreas verdes da região.

A pertinência do assunto é moldada pela atual discussão sobre a importância das áreas verdes para o contexto das cidades, como área de equilíbrio psicofísico, identidade, lazer e turismo.

Para os objetivos propostos, as duas etapas metodológicas mostraram ser eficientes ao fornecer resultados que podem contribuir para a gestão turística do Parque do Ingá, pois alcançou a proposição de identificar os pontos de maior potencialidade turística do parque.

\section{REFERÊNCIAS}

ANDRADE, J. V. Turismo Fundamentos e Dimensões. São Paulo: Ática, 2006. 216p.

BOBROWSKI, R; BIONDI, D.; VASHCHENKO, Y. Qualidade visual da paisagem do Parque Natural Municipal Tanguá, Curitiba - PR. Revista da Sociedade Brasileira de Arborização Urbana, Piracicaba, v. 5, n. 2, p. 19-39, 2010.

BOVO, M. C; AMORIM, M. C. Análise e diagnósticos dos parques urbanos em Maringá (PR) Brasil. Revista Geo UERJ, Rio de Janeiro, v. 2, n. 22, p. 323-349, 2011. 
BUCCHERI FILHO, A. T; NUCCI, J. C. Espaços Livres, Áreas Verdes e Cobertura Vegetal no Bairro Alto da XV, Curitiba - PR. Revista do Departamento de Geografia, Curitiba, v. 18, n. 18, p. 48-59, 2006.

BULUT, Z.; YILMAZ, H. Determination of landscape beauties through visual quality assessment method: a case study for Kemaliye (Erzincan/Turkey). Environmental Monitoring and Assessment, Amsterdam, v. 141, n. 1-3, p.121-129, 2008.

CANTERAS, J. C. Introducción al paisaje. Curitiba: UFPR, Universidad de Cantabria, 1992. $60 p$.

DE ANGELIS, B; LOBODA, C. R. Áreas verdes públicas urbanas: Conceitos, usos e funções. Ambiciência, Guarapuava, PR, v. 1, n. 1, p. 125-139, 2005.

DIAS, K. Entre visão e invisão: Paisagem (por uma experiência da paisagem no cotidiano). Brasília: Ed. UNB, 2010. 300p.

GUZZO, P; CARNEIRO, R.M.A; OLIVEIRA, H. Cadastro Municipal de Espaços Livres Urbanos de Ribeirão Preto (SP): Acesso Público, Índices e Base para Novos Instrumentos e Mecanismos de Gestão. Revista da Sociedade Brasileira de Arborização Urbana, Piracicaba, v. 1, n. 1, p. 19-30, 2006.

HENZ, A. P; OLIVEIRA, J. P. A. Paisagem como potencial turístico de Foz do Iguaçu: Um estudo exploratório da paisagem do Parque Nacional do Iguaçu e da Usina Hidrelétrica de Itaipu. Revista Turismo Visão e Ação - Eletrônica, Itajaí, v. 12, n. 2, p. 172-183, 2010.

LEMES, F. B. M; NEVES, S. C. Dos ecos do turismo aos ecos da paisagem: analises das tendências do ecoturismo e a percepção de suas paisagens. Revista de Turismo y Patrimônio Cultural, Passos, v. 5, n. 2, p. 209-223, 2007.

MANSANO, C. N; SARRÃO, A; SARRÃO, C. Percepção da paisagem de alguns frequentadores do Parque do Ingá na cidade de Maringá - PR. In: I SEURB - SIMPÓSIO DE ESTUDOS URBANOS: DESENVOLVIMENTO REGIONAL E DINÂMICA AMBIENTAL, 2011, Campo Mourão. Anais... Campo mourão: FELCICAM, 2011. p.1-26.

MAZZEI, K.; COLSESANTI, M. T. M.; SANTOS, D. G. Áreas verdes urbanas, espaços livres para o lazer. Sociedade \& Natureza, Uberlândia, Minas Gerais, v. 19, n.1, p.33-43, 2007.

MORERO, A. M.; SANTOS, R. F.; FIDALGO, E. C. C. Planejamento ambiental de áreas verdes: estudo de caso de Campinas-SP. Revista do Instituto Florestal, v. 19, n. 1, p. 19-30, 2007.

PIRES, P.S.A. Avaliação da qualidade visual da paisagem na região carbonífera de CriciúmaSC. Dissertação (Mestrado em Engenharia Florestal) - Setor de Ciências Agrárias, Universidade Federal do Paraná, Curitiba, 1993.

PIRES, P. S. A paisagem litorânea como recurso turístico. In: YÁZIGI, Eduardo; CRUZ, Rita; CARLOS, Ana F. (Org.). Turismo: espaço, paisagem e cultura. São Paulo: HUCITEC, 1999. p. 161-179.

PIRES, P. S. A análise de indicadores da qualidade visual como etapa da caracterização de paisagens turísticas: uma aplicação no distrito-sede de Porto Belo-SC. Turismo-Visão e Ação, Itajaí, v. 7, n. 3, p. 417-426, 2005. 
SERPA, A. Gestão territorial do sistema de parques públicos em Salvador, Bahia: Contradições e paradoxos. Revista RA'E GA, Curitiba, v. 12, n. 12, p. 07-19, 2006.

SILVA, R. R. S; BIONDI, D; YAMAMURA, M; SILVA, D. A. T. Avaliação da qualidade e diversidade da paisagem do Parque São Lourenço para fins recreativos e turísticos. Revista da Sociedade Brasileira de Arborização Urbana, Piracicaba, v. 7, n. 4, p. 53-68, 2012.

SILVA, R. R. S; BIONDI, D. Avaliação da Preferência paisagística no Jardim Botânico de Curitiba, Paraná, Brasil. Revista da Sociedade Brasileira de Arborização Urbana, Piracicaba, v. 8, n. 1, p.39-53, 2013.

TOLEDO, F. S.; SANTOS, D. G. Espaços livres de construção. Revista da Sociedade Brasileira de Arborização Urbana, Piracicaba, v. 3, n.1, p. 73-91, 2008.

VIEIRA, C. H. S. D.; KOZERA, C. BIONDI, D. Preferência visual de paisagens do Parque Municipal do Passaúna, Curitiba, PR. Paisagem e Ambiente, São Paulo, v. 24, p. 421-430, 2007. 